\title{
Friedreich's Ataxia: A New Mutation in Two Compound Heterozygous Siblings with Unusual Clinical Onset
}

\author{
Laura Doria Lamba ${ }^{a}$ Paola Ciottic Gaia Giribaldi ${ }^{a}$ Emilio Di Maria ${ }^{c}$ Alessandra Varese ${ }^{c}$ \\ Mauro Di Stadio $^{b}$ Angelo Schenone ${ }^{d}$ Paola Mandich ${ }^{c}$ Emilia Bellone $^{c}$ \\ Department of Neuroscience, Ophthalmology and Genetics, University of Genoa, \\ a Pediatric Neuropsychiatry Operative Unit, and ${ }^{b}$ Operative Unit of Orthopedics, G. Gaslini Institute, \\ ${ }^{c}$ Genetics Operative Unit, and ${ }^{\mathrm{d}}$ Neurology Operative Unit, S. Martino Hospital, Genoa, Italy
}

Dear Sir,

Friedreich's ataxia (FA) is the most common autosomal recessive ataxia; a recent European epidemiological study estimated the disease incidence at 1 in 29,000 individuals [1].

Disease onset usually occurs between the first and second decade of life and is characterized by progressive limb and truncal ataxia and loss of deep tendon reflexes. Afterwards, dysarthria, Babinski sign and loss of vibration and joint position sense are frequently present. Hypertrophic cardiomyopathy, skeletal deformities (scoliosis, pes cavus and hammer toe), diabetes mellitus, optic atrophy, nystagmus and sensorineural deafness may also be associated $[1,2]$.

Mild abnormalities of motor nerve conduction velocity and reduced or absent sensory compound action potential amplitudes are frequently observed [3].

The clinical course is progressive with loss of deambulation after an average of 15 years from the onset of symptoms. Clinical diagnosis may be complicated by phenotypic variability, and differential diagnosis includes Charcot-Marie-Tooth disease, autosomal dominant spinocerebellar ataxia [4] and ataxia with isolated vitamin E deficit, a rare autosomal recessive neurodegenerative disease caused by mutations in the $\alpha$-tocopherol transfer protein gene which is responsive to vitamin E supplementation [5]. The most common muta- tion causing FA is an expanded GAA repeat in the gene encoding the frataxin protein [6]. Ninety-six percent of patients are homozygous for GAA expansion. Frataxin point mutations have been found in the remaining patients who are heterozygous for the expanded allele [7].

The phenotypic features of patients harboring point mutations may include classical symptomatology or may differ from classic FA [7, 8].

We report on 2 siblings with atypical clinical presentation during the first years of the disease, which caused initial clinical confusion and a delay in making a correct diagnosis.

Molecular testing demonstrated that both patients are compound heterozygous for GAA expansion and have a novel point mutation (c.165 + 1 G $\rightarrow$ A) which involves the consensus GT dinucleotide in the $3^{\prime}$ splice acceptor site of intron 1 of the frataxin gene.

\section{Case Report}

\section{Patient 1 (IV-3)}

The patient, a 20-year-old woman from southern Italy, was referred to our institute at the age of 14 years due to difficulty in walking. She is the third-born child of unrelated, healthy parents. At the time, she had a healthy 23-year-old brother and an- other 25-year-old brother who had a great deal of difficulty in walking, though more detail was not available.

The patient had normal motor milestones; then, at the age of 7 years, she presented progressive difficulty in walking, and pes cavus was noticed.

Her first neurological examination was performed at 14 years of age and showed normal mental status and language function; however, distal muscle weakness and atrophy of all 4 limbs, which was more pronounced in the lower extremities, pes cavus with foot drop and bilateral Achilles tendon retraction, areflexia, absent plantar response without Babinski sign and steppage gait were observed; vibration and joint position sense was reduced. Extraocular movements were full without nystagmus, and optic disks were normal.

Electrophysiological investigation was performed at the age of 14 years with the use of surface electrodes. The patient's skin temperature was at least $32^{\circ} \mathrm{C}$ during the testing which revealed low amplitude of both the compound muscle action potentials, as measured peak to peak of the median and common peroneal nerves with a mild reduction in motor nerve conduction velocities (MNCVs), as well as the absence of sensory action potentials of the median nerves. Somatosensory short-latency-evoked potentials showed marked attenuation and latency delay for N13, N19

\section{KARGER}

Fax +4161306 1234 E-Mail karger@karger.ch www.karger.com
(ㄷ) 2009 S. Karger AG, Basel 0014-3022/09/0614-0240\$26.00/0

Accessible online at: www.karger.com/ene
Laura Doria Lamba, MD

Divisione di Neuropsichiatria Infantile

Istituto G. Gaslini, Lgo G. Gaslini 5

IT-16100 Genoa (Italy)

Tel. +39 010563 6702, Fax +39010 381 303, E Mail lauradoria@ospedale-gaslini.ge.it 


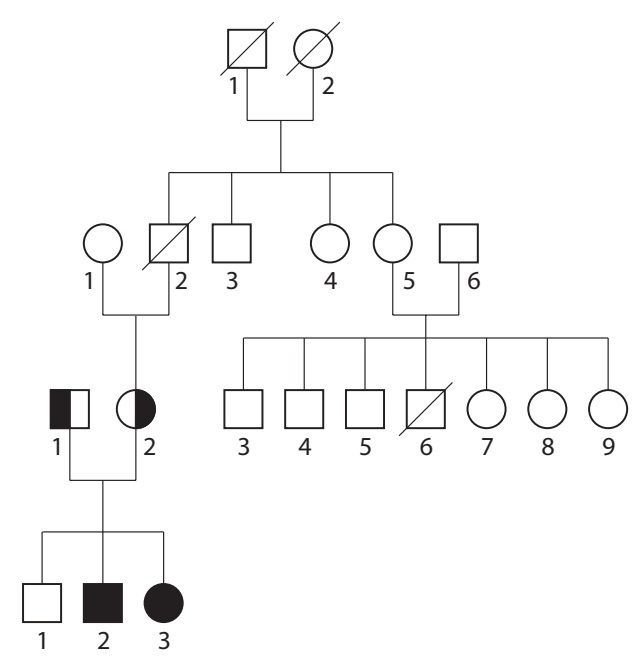

Fig. 1. Pedigree.

and P37. Brain and whole spinal MRI were unremarkable.

At the age of 15 years, she underwent surgery for foot deformity.

A sural nerve biopsy was obtained at mid-calf under local anesthesia. Nerve specimens were fixed in glutaraldehyde $2.5 \%$ in cacodylate buffer 0.025 molar and processed by light and electron microscopy.

The sural nerve biopsy showed a severe loss of myelinated fibers; we found several fibers showing thinner myelin sheath compared with axon diameter, and small onion bulb formations.

The patient was initially diagnosed with peripheral neuropathy; $17 \mathrm{p} 11.2 \mathrm{du}-$ plication/deletion was ruled out by pulsedfield gel electrophoresis analysis.

Afterwards, she developed progressive disequilibrium, and at the age of 17 , she was only able to walk with external support. Diabetes and scoliosis were absent, and electrocardiography and echocardiography were within normal limits. The patient did not develop dysarthria, nystagmus or optic atrophy.

Due to the progressive ataxia and disequilibrium with loss of deambulation, a more accurate evaluation was carried out. Family history revealed the presence of a brother with severe walking disabilities, thus raising a diagnostic suspicion of neurodegenerative ataxia. Therefore, vitamin E levels were measured and found to be within the normal range. Molecular investigation for FA was also performed.

\section{Patient 2 (IV-2)}

The patient, a 31-year-old man, is the brother of patient 1 (fig. 1). He was referred to us for clinical evaluation at age 24 years in the context of the family study.

He had normal motor milestones and progressive difficulties in deambulation associated with distal weakness of the lower limbs and pes cavus starting from the age of 6 years, at which time, however, he presented no signs of cerebellar compromission.

Over the following years, he showed relevant muscle wasting, which was more pronounced in the lower limbs, and impairment of deep sensitivity. Moreover, the patient developed progressive scoliosis.

Clinical picture, electrophysiological investigation and sural nerve biopsy were performed elsewhere. Nerve biopsy revealed a $50 \%$ axonal degeneration of the nervous fibers that were examined, leading to a consequent diagnostic suspicion of axonal neuropathy, mainly of the sensitive type.

The patient was referred to us for evaluation at 24 years of age. He also developed insulin-dependent diabetes at that time.

Neurological examination revealed normal mental status and speech, relevant muscle wasting and weakness which was more pronounced in the distal lower limbs, loss of deep tendon reflexes, absent cutaneous plantar response, pes cavus and bilateral Achilles tendon retraction.

The patient presented disequilibrium in the standing position and marked ataxic gait requiring external support, though other signs of cerebellar compromission were not observed. Extraocular movements were full without nystagmus, optic disks were flat without pallor, and cardiac symptoms were absent.

We performed electrophysiological investigations that showed a mild reduction in MNCV of the median and peroneal nerves with reduced compound muscle action potential amplitude, and marked reduction in amplitude of the sensory action potential of the median nerve (table 1). Somatosensory short-latency-evoked potentials were not performed.

Brain and whole spinal MRI were unremarkable.

The marked impairment of equilibrium and gait ataxia were highly suggestive of evolutive ataxia, and the presence of insulin-dependent diabetes supported the diagnostic suspicion. Therefore, molecular analysis for FA was performed.

\section{Genetic Study}

Accurate molecular analysis for FA was performed in both siblings as described by Ciotti et al. [9]. PCR analysis of the GAA triplet repeat in frataxin intron 1 revealed that both siblings had 1 expanded allele with an estimated 1,000 triplet repeats, while the other was within the normal range, thus suggesting carrier status.

Analysis of the parents revealed that the patients' father was a carrier of 1 expanded allele (1,000 triplet repeats), whereas the mother had 2 non-expanded alleles.

This suggested a condition of compound heterozygosity in the 2 patients who have 1 expanded allele while the other allele bears a distinct mutation of the frataxin gene.

DNA sequencing in both patients revealed a single-base substitution (c.165 + 1 $\mathrm{G} \rightarrow \mathrm{A}$ ), located at the $3^{\prime}$ splice acceptor site of frataxin intron 1 , which destroys the invariant GT acceptor sequence. No other abnormalities were found in sequencing exons 1-5a or in the adjacent portions of intervening introns. The frataxin gene of both healthy parents was sequenced in order to confirm that this variant was on a distinct allele from the expanded repeat. The mother had the same variant, but lacked 1 expanded triplet repeat, suggest- 
Table 1. Electrophysiological investigations

\begin{tabular}{|c|c|c|c|c|c|c|c|c|}
\hline & \multicolumn{6}{|l|}{ MNCV } & \multirow{2}{*}{\multicolumn{2}{|c|}{$\frac{\text { SNCV }}{\text { median nerve }}$}} \\
\hline & \multicolumn{3}{|c|}{ peroneal nerve } & \multicolumn{3}{|c|}{ median nerve } & & \\
\hline & $\begin{array}{l}\mathrm{MNCV} \\
\mathrm{m} / \mathrm{s}\end{array}$ & $\begin{array}{l}\text { distal laten- } \\
\mathrm{cy}, \mathrm{s}\end{array}$ & $\begin{array}{l}\text { CMAP ampli- } \\
\text { tude, mV }\end{array}$ & $\begin{array}{l}\mathrm{MNCV} \\
\mathrm{m} / \mathrm{s}\end{array}$ & $\begin{array}{l}\text { distal laten- } \\
\text { cy, ms }\end{array}$ & $\begin{array}{l}\text { CMAP ampli- } \\
\text { tude, } \mathrm{mV}\end{array}$ & $\begin{array}{l}\mathrm{SNCV} \\
\mathrm{m} / \mathrm{s}\end{array}$ & $\begin{array}{l}\text { SAP ampli- } \\
\text { tude, mV }\end{array}$ \\
\hline Standard adult values & $>40$ & $<5$ & $>5$ & $>50$ & $<3$ & $>7$ & $>44$ & $>14$ \\
\hline Patient IV.3 (14 years) & 36.5 & 4.9 & 4 & 48.8 & 3.3 & 6 & n.e. & \\
\hline Patient IV.2 (28 years) & 40 & 3.9 & 3 & 44.9 & 3.4 & 5 & 50 & 5 \\
\hline
\end{tabular}

SNCV $=$ Sensory nerve conduction velocity; CAMP = compound muscle action potential; $\mathrm{SAP}=$ sensory action potential; $\mathrm{n} . \mathrm{e} .=$ not evaluable.

ing that these mutations are inherited as distinct alleles. This variant was absent in 50 unrelated control individuals.

We were not able to perform mRNA studies to evaluate the frataxin expression because the family was not willing to undergo further blood sampling to obtain RNA.

\section{Discussion}

Our patients presented with marked distal weakness, evident foot deformity with pes cavus and marked steppage in deambulation.

The absence of gait and/or trunk ataxia (unlike what is commonly reported in the literature) and of Babinski sign at disease onset were misleading, and the initial clinical presentation appeared to be suggestive of primary peripheral neuropathy.

Only afterwards did both patients show relevant muscle wasting, which was more pronounced in the lower limbs, impaired deep sensitivity and marked ataxic gait requiring external support, thus suggesting FA.

Electrophysiological examination revealed mild axonal alterations with mild slowing of motor nerve conduction velocity and a more marked compromission of the sensory pathways (table 1), all of which were compatible with a diagnosis of FA and even with primary peripheral compromission of the nervous system. In fact, severe clinical compromission, despite only mild electrophysiological alterations, is not uncommon in peripheral polyneuropathies, which frequently do not show any direct correlation between clinical and electrophysiological phenotype.
The subsequent clinical evolution of patient 1 suggested a possible diagnosis of FA, and an accurate report of the family history allowed us to identify the patient's brother who had similar clinical signs but a more advanced and therefore more expressive stage of illness with marked ataxic gait, which is uncommon in peripheral neuropathies.

Differential diagnostic procedures were carried out in an attempt to rule out ataxia with isolated vitamin E deficit [5], which can cause a clinical phenotype similar to FA associated with mild to moderate axonal sensory neuropathy that is usually less severe than in FA.

Finally, identifying compound heterozygosity in both siblings provided us with confirmation of the diagnosis of FA.

Various authors [10-13] have reported an incidence of $2-5 \%$ of compound heterozygosity among patients affected by FA.

Expansion of the GAA repeat in the first intron of the frataxin gene is by far the most common DNA abnormality causing frataxin deficiency, possibly by interfering with gene transcription. Suppression of frataxin expression by GAA expansion is not complete and appears to be proportional to repeat length. Accordingly, expansion size in patients who are homozygous for GAA repeat expansion inversely correlates with age at onset, disease severity and the time of wheelchair confinement [12-15]. Some authors even correlate larger triplet expansion with increased frequency of cardiomyopathy [12].

The milder clinical presentation that is observed in individuals with smaller GAA repeat sizes is likely due to the higher residual levels of frataxin that are present in these patients $[16,17]$.
Most of the time compound heterozygotes are clinically undistinguishable from FA patients with homozygous GAA expansions, although their clinical phenotype may vary from classical to atypical forms with different degrees of severity $[8,18]$.

Atypical clinical presentation of compound heterozygosity may include absence of dysarthria, Babinski sign, limb ataxia, hypertrophic cardiomyopathy, as was observed in both our patients, and the absence of diabetes, as was the case in patient 1 .

Different types of FRDA point mutations have been reported in the literature: nonsense mutations, errors of splicing or frameshift mutations that result in premature termination of translation, and missense mutations, mainly involving the highly conserved, carboxy-terminal domain.

The effects on protein translation and function may vary from mild to severe, depending on the type of mutation $[7,18]$.

Despite the general genotype-phenotype correlation, it is not possible to predict the specific clinical outcome of individual cases.

We report a novel mutation (c.165 + 1 $\mathrm{G} \rightarrow \mathrm{A}$ ) which involves the consensus GT dinucleotide in the $3^{\prime}$ splice donor site of intron 1, suggesting exon 2 skipping. The absence of this exon in the frataxin mRNA may be the cause of a nonfunctional protein. It is assumed that the expanded allele could contribute to the phenotype in patients who are compound heterozygotes [13], but we are currently unable to quantify this contribution.

To our knowledge, this is the first report of FA mimicking hereditary motor 
and sensory neuropathy (HMSN) to be genetically defined by compound heterozygosity.

In the literature, there are some reports of patients with FA presenting with clinical features of both HMSN and FA, but none of the patients have been genetically investigated [19,20], except for the ones reported by Panas et al. [21]. The authors describe 4 patients from 3 unrelated families presenting with clinical and electrophysiological features of HMSN. Molecular genetic analysis revealed the intronic GAA trinucleotide repeat expansion in the X25 gene on chromosome 9q13-21.1, and the patients were diagnosed with FA. Neurophysiological alterations were suggestive of demyelinating neuropathy with a marked reduction in $\mathrm{MNCV}$, a finding which would exclude a diagnosis of FA according to Harding's criteria.

Our patients presented with the initial clinical features of HMSN; electrophysiological testing revealed axonal, mainly sensitive alterations, as are commonly observed in FA.

Unfortunately, sural nerve biopsies were performed in 2 different laboratories. They revealed considerable differences in the neuropathological features of the 2 siblings. In fact, patient 1 showed axonal loss and clear signs of de- and remyelination, as already reported in the literature [22, 23], whereas her brother had axonal neuropathy. Demyelination in patient 1 may also have been secondary to axonal atrophy.

We stress that a diagnosis of FA should be taken into consideration in patients with initial clinical presentation of peripheral neuropathy with early prevalent peripheral sensitive impairment and only subsequent trunk and/or gait ataxia.

Lastly, we would like to highlight the importance of taking family history into account when attempting to make a diagnosis.

\section{References}

1 Delatycki, Williamson R, Forrest SM: Friedreich's ataxia: an overview. J Med Genet 2000;37:1-8.

$\checkmark 2$ Harding AE: Friedreich's ataxia: a clinical and genetic study of 90 families with an analysis of early diagnosis criteria and intrafamilial clustering of clinical features. Brain 1981;104:589-620.
-3 Santiago-Perez S, Perez-Conde MC, UgaldeCanitrot A, Lopez-Pajares MR: A neurophysiological study of the alterations to the central and peripheral nervous systems in Friedreich's ataxia. Rev Neurol 2007;44:193197.

4 Harding AE: The Hereditary Ataxias and Related Disorders. Edinburgh, Churchill Livingstone, 1984.

5 Doria-Lamba L, De Grandis E, Cristiani E, Fiocchi I,Montaldi L, Grosso P, Gellera C: Efficacious vitamin $\mathrm{E}$ treatment in a child with ataxia with isolated vitamin $\mathrm{E}$ deficiency. Eur J Pediatr 2006;165:494-495.

-6 Campuzano V, Montermini L, Moltò MD, Pianese L, Cossée M, Cavalcanti F, Monros E, Rodius F, Duclos F, Monticelli A, Zara F, Canizares J, Koutnikova H, Bidichandani SI, Gellera C, Brice A, Trouillas, De Michele G, Filla A, De Frutos R, Palau F, Patel PI, Di Donato S, Mandel J-L, Cocozza S, Koenig M, Pandolfo M: Friedreich's ataxia: autosomal recessive disease caused by intronic GAA triplet repeat expansion. Science 1996;271: 1423-1427.

7 Cossee M, Durr A, Schmitt M, Dahl N, Trouillas P, Allinson P, Kostrzwa M, Nivelon Chevallier A, Gustavson KH, Kohlschutter A, Muller U, Mandel JL, Brice A, Koenig M, Cavalcanti F, Tammaro A, De Michele G Filla A, Cocozza S, Labuda M, Montermini L, Poirier J, Pandolfo M: Friedreich's ataxia: point mutations and clinical presentation of compound heterozygotes. Ann Neurol 1999; 45:200-206.

-8 McCormack M, Guttmann RP, Schumann M, Farmer JM, Stoole CA, Campuzano V, Koenig M, Lynch DR: Frataxin point mutations in two patients with Friedreich's ataxia and unusual clinical features. J Neurol Neurosur Psychiatry 2000;68:661-664.

$\checkmark 9$ Ciotti P, Di Maria E, Bellone E, Ajmar F, Mandich P: Triplet repeat primed PCR (TP PCR) in molecular diagnostic testing for Friedreich ataxia. J Mol Diagn 2004;6:285289.

10 Zhu D, Burke C, Leslie A, Nicholson GA: Friedreich's ataxia with chorea and myoclonus caused by a compound heterozygosity for a novel deletion and the trinucleotide GAA expansion. Mov Disord 2002; 17:585589.

-11 Spacey SD, Szczygielski BI, Young SP, Hukin J, Selby K, Snutch TP: Malaysian siblings with Friedreich ataxia and chorea: a novel deletion in the frataxin gene. Can J Neurol Sci 2004;31:383-386.

12 Monros E, Molto MD, Martinez F, Canizares J, Blanca J, Vilchez JJ, Proeto F, De Frutos R, Palau F: Phenotype correlation and intergenerational dynamics of the Friedreich ataxia GAA trinucleotide repeat. Am J Hum Genet 1997;61:101-110.
13 De Castro M, Garcia-Plannes J, Monros E, Canizares J, Vasquez Manrique R, Vilchez JJ, Urtasun M, Lucas M, Navarro G, Izquierdo G, Molto MD, Palau F: Genotype and phenotype analysis of Friedreich's ataxia compound heterozygous patients. Hum Genet 2000;106:86-92.

14 Filla A, de Michele G, Cavlcanti F, Pianese L, Monticelli A, Campanella G, Cocozza S: The relationship between trinucleotide (GAA) repeat length and clinical features in Friedreich ataxia. Am J Hum Genet 1996;59:554560 .

$\checkmark 15$ Delatycki MB, Paris DB, Gardner RJ, Nicholson GA, Nassif N, Storey E, MacMillan JC, Collins V, Williamson R, Forrest SM: Clinical and genetic study of Friedreich ataxia in an Australian population. Am J Med Genet 1999;87:168-174.

16 Campuzano V, Montermini L, Lutz Y, Cova L, Hindelang C, Jiralerspong S, Trottier Y, Kish SJ, Faucheux B, Trouillas P, Authier FG, Durr A, Mandel JL, Vescovi A, Pandolfo M, Koenig M: Frataxin is reduced in Friedreich ataxia patients and is associated with mitochondrial membranes. Hum Mol Genet 1997;6:771-780.

-17 Oshima J, Montermini L, Wells RD, Pandolfo M: Inhibitory effects of expanded GAA-TTC triplet repeats from intron I of the Friedreich ataxia gene on transcription and replication in vivo. J Biol Chem 1998;273: 14588-14595

18 Forrest MF, Knight M, Delatycki MB, Paris D, Williamson R, King J, Yeung L, Nassif N, Nicholson GA: The correlation of clinical phenotype in Friedreich ataxia with the site of point mutations in the FRDA gene. Neurogenetics 1998;1:253-257.

19 McKusick V: Charcot-Marie-Tooth peroneal muscular atrophy and Friedreich's ataxia, combined; in McKusick V (ed): Mendelian Inheritance in Men. Baltimore, Johns Hopkins University Press, 1992, pp 1798.

20 Salisachs P, Findley LJ, Codina M: A case of Charcot-Marie-Tooth's disease mimicking Friedreich's ataxia: is there any association between Friedreich's ataxia and CharcotMarie-Tooth's disease? Can J Neurol Sci 1982;9:99-103.

21 Panas M, Kalfakis N, Karadima G, Davaki P, Vassilopoulus D: Friedreich's ataxia mimicking hereditary motor and sensory neuropathy. J Neurol 2002;249:1583-1588.

22 Ceruso G, Santoro L, Peretti A, Serlenga L, Crisci C, Ragno M, Barbieri F, Filla A: Friedreich's ataxia: electrophysiological and histological findings. Acta Neurol Scand 1983; 67:26-40

23 Jitpimolmard S, Small J, King RH, Geddes J, Misra P, McLaughlin J, Muddle JR, Cole M, Harding AE, Thomas PK: The sensory neuropathy of Friedreich's ataxia: an autopsy study of a case with prolonged survival. Acta Neuropathol 1993;86:29-35. 